\title{
The Evaluation of Relationship Between Dimensions of Organizational Structure and Safety and Health Situation in Stone Industries
}

\section{ARTICLE INFO}

\section{Article Type}

Original article

\section{Authors}

Ali Hosseini ${ }^{1}$, M.Sc

Hossein Akbari², PhD

Abbas Bahrami ${ }^{3 *}, \mathrm{PhD}$

Fahimeh Karamali ${ }^{1}, \mathrm{PhD}$

1 Department of health, Safety and Environment Management, School of Health, Kashan University of Medical Sciences, Kashan, Iran.

${ }^{2}$ Assistant Professor of Biostatistics, School of Public Health, Kashan University of Medical Sciences, Kashan, Iran. 3 Social Determinants of Health (SDH) Research Center, Faculty of Health, Kashan University of Medical Sciences, Kashan, Iran

\footnotetext{
*Corresponding Author

Address: Social Determinants of Health (SDH) Research Center, Faculty of Health, Kashan University of Medical Sciences, Kashan, Iran.

Phone: 00983155540021

Fax: 00983155550111

bahrami_a@kaums.ac.ir
}

\section{ABSTRACT}

Introduction \& Objective: Organizational factors are one of the main causes of unsafe practices and inappropriate conditions of working environment. Where a technical defect or a simple human error alone cannot be used as an explanation for the occurrence of accidents. The purpose of this study was to investigate the relationship between organizational structure dimensions and safety and health status in stone industries.

Methods: This descriptive study was performed in stone industry factories of Mahmoud Abad industrial town of Isfahan in year 2020. For data collection, it used Robins organizational structure standard questionnaire and ELMERI safety and health checklist. The sample size consisted of 90 stone factories. After collecting information, the score of each questionnaire was calculated and converted on the basis of 100. For quantitative variables, independent t-test and ANOVA tests were used. Chi-square test was used for qualitative variables. For multivariate analysis, multiple linear regression analysis was carried out.

Results: The coefficient of linear correlation between overall score of organizational structure with safety situation for Saab and Ghulebor stations were -0.348 and $-0.232(\mathrm{P}<0.05)$, respectively. At Saab station, the highest number of cases was related to safe behaviors with an average of 74.4 and the lowest was industrial health with an average of 45.8. At Ghulebor station, score of 65.6 was related to fire safety and first aid, industrial health had a score of 45.8. The highest linear correlation at Ghulebor and Saab station was between safety and health with recognition (-0.531) (-0.626).

Conclusion: The results of the present study showed safety and health can be improved by modifying the organizational structure. Organizations with horizontal and vertical complexity, focus, instructions, formal correspondence, rules and regulations have a greater impact on safety and health status.

Keywords: Safety; Health; Organizational structure; Stone industries. 
همبستكى خطى در ايستخاه قلهبر و ساب، بين نمره كلى ايمنى و بهداشت

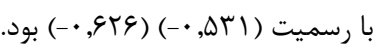

نتيجهَيرى: نتايج مطالعه حاضر نشان داد كه وضعيت ايمنى و بهداشت مى تواند با اصلاح وضعيت ساختار سازمانى بهبود يابد. سازمانهاى با بان

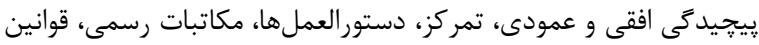

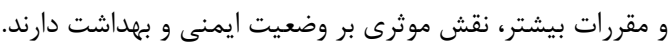

كليد وازمها: ايمنى؛ بهداشت؛ ساختار سازمانى؛ صنايع سنگ.

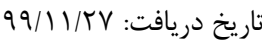

تاريخ يذيرش:

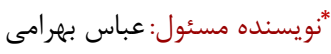

مقدمه

براساس اعلام سازمان بين المللى كار ؛ سالانه Vrr ميليون حادثه شغلى

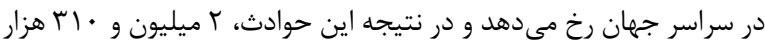

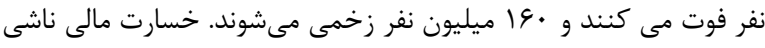

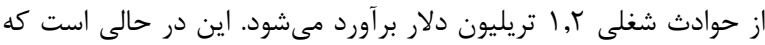

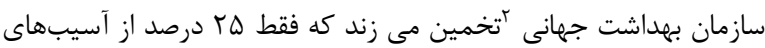

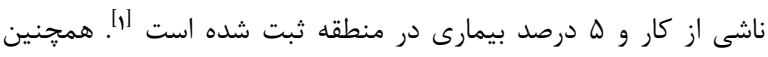

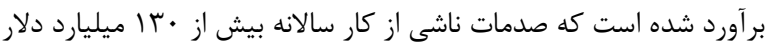

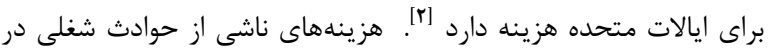

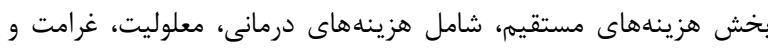

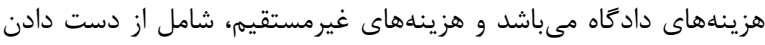

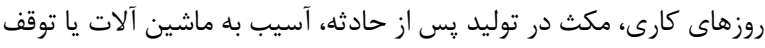

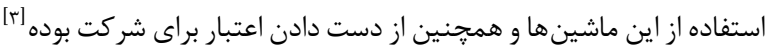

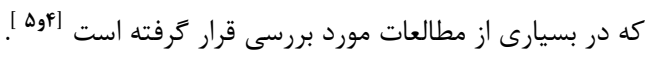

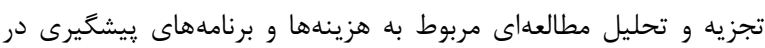

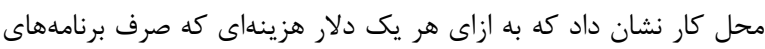

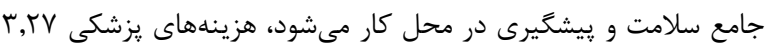

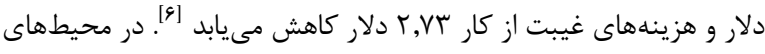

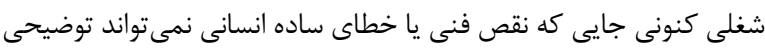

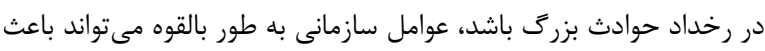

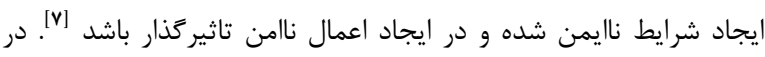

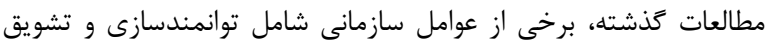

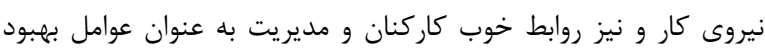

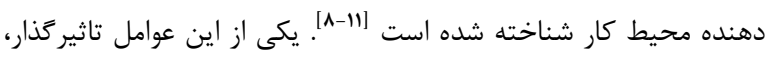

World Health Organization (WHO)

\section{بررسى رابطه بين ابعاد ساختار سازمانى و وضعيت ايمنى و بهداشت در صنايع سنَ رسى}

\section{على حسينى '، حسين اكبرى ؟، عباس بهرامى ׳*، فهيمه كرمعلى'}

' كروه مديريت سلامت، ايمنى و محيط زيست HSE-MS، دانشكده بهداشت، دانشعاه علوم يزشكى كاشان، كاشان، ايران.

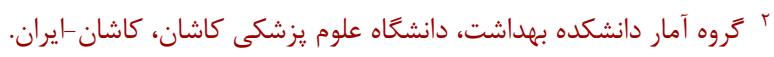

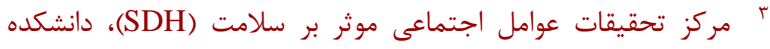
بهداشت، دانشخاه علوم يزشكى كاشان، كاشان، ايران.

جكيده مقدمه و هدف: عوامل سازمانى يكى از موارد اساسى ايجاد اعمال نا ايمن و شرايط نامناسب محيط كار هستند. جايى كه نقص فنى يا خطاى ساده

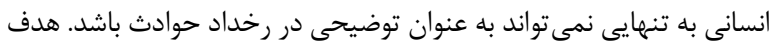

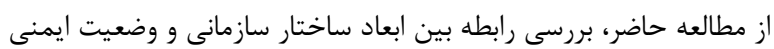

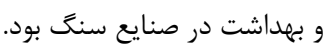
روش يروهش: اين مطالعه توصيفى در سال 99 ا ادر كارخانهاى صنايع سنَ شهرك صنعتى محمود آباد اصفهان انجام شد. براى جمع آورى دادهها

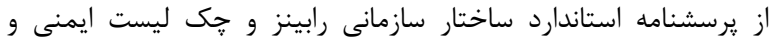

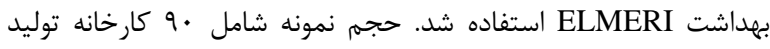

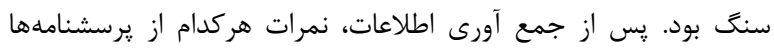

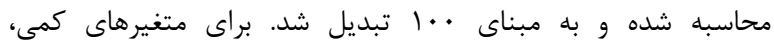

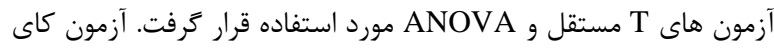
اسكوئر براى متغيرهاى كيفى استفاده شد. براى تحليل خند آند متغيره،

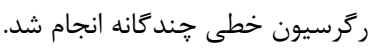

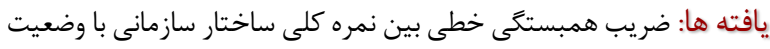

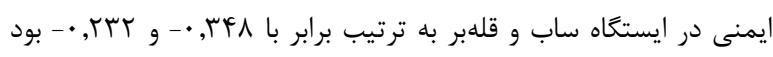

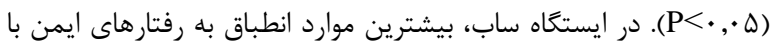

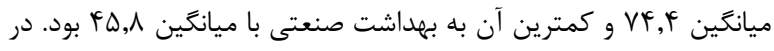

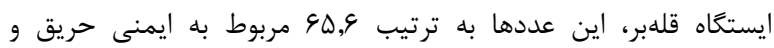

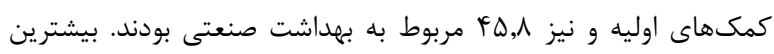

International Labour Organization (ILO)

دانشنامه صارم در طب بارورى

دوره ه، شماره f) - زمستان 
كدام از خرده مقياسهاى ساختار سازمانى است. اعتبار يرسشنامه مذكور

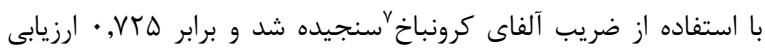

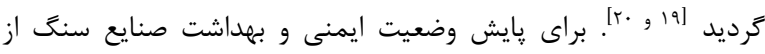

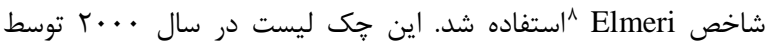

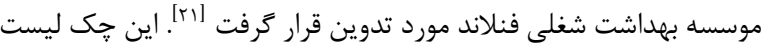

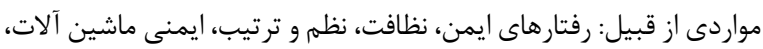

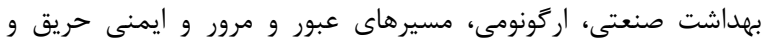

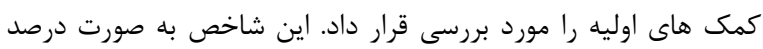

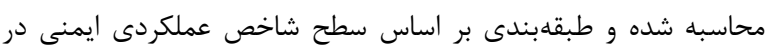

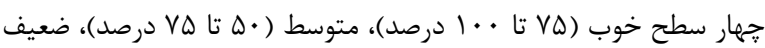

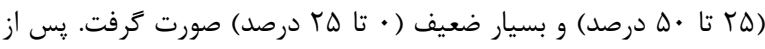

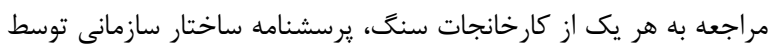

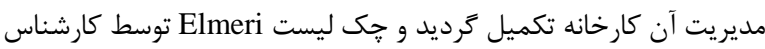

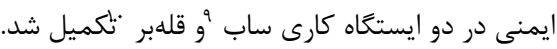

تجزيه و تحليل آمارى

براى تحليل اطلاعات، ابتدا آزمون كولموكروف-اسميرنوف 'براى سنجش

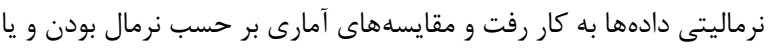

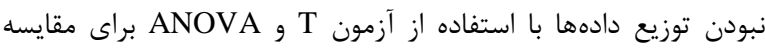

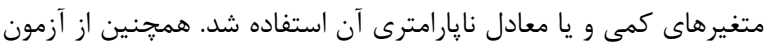

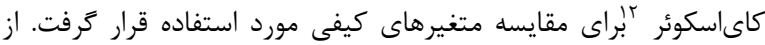

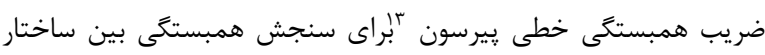

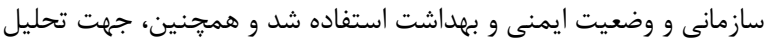

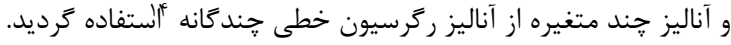

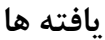

در اين يزوهش، از اطلاعات •و كارخانه سنَّبرى در استان اصفهان

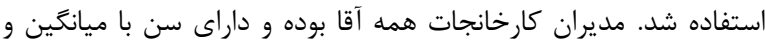

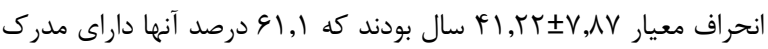

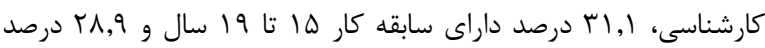

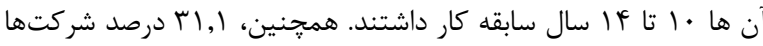

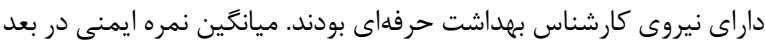

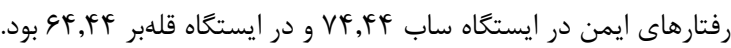

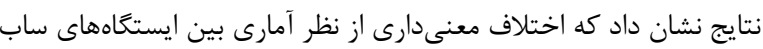

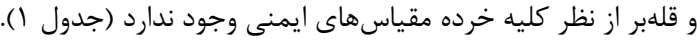

Polish Station Cutter Station Kolmogorov-Smirnov Test Chi-square Test Pearson's Linear Correlation Coefficient ' Multiple Linear Regression (MLR) ${ }^{1}$

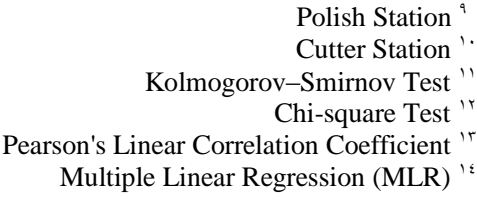

ساختار سازمانى مىباشد [rا] كه الخو، نقشه ارتباطات و تعاملات ميان

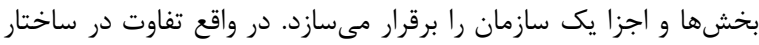

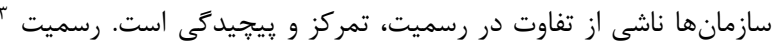

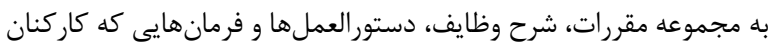

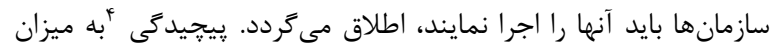

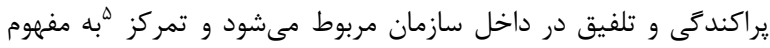

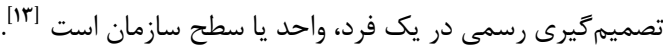

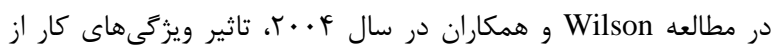

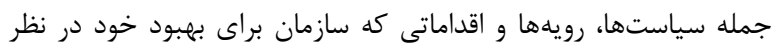

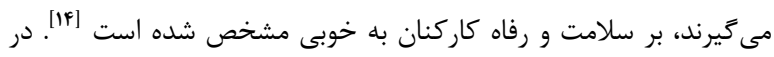

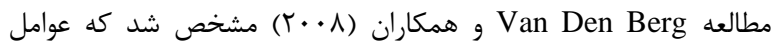

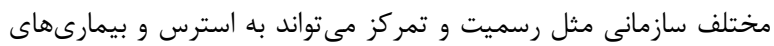

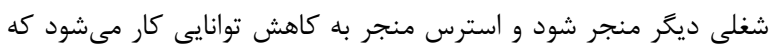

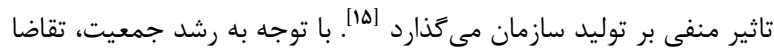

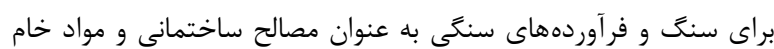

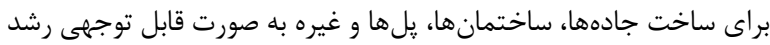

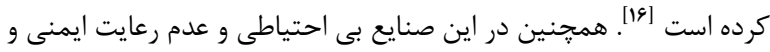

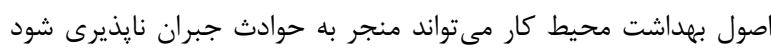

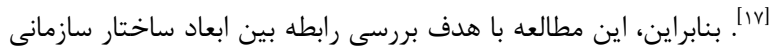

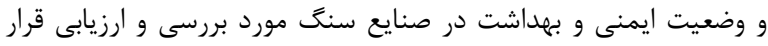

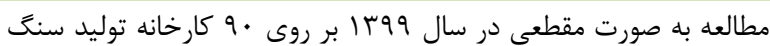

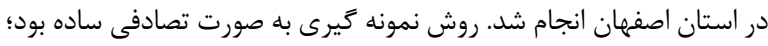

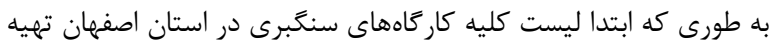

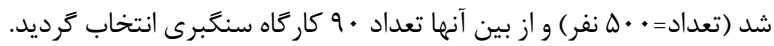

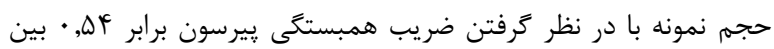

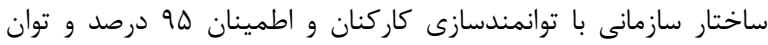

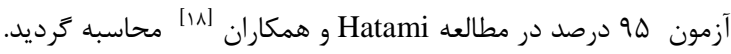

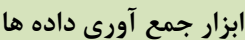

ابزار گردآورى اطلاعات در مطارئ داده هالعه حاضر، يرسشنامه سنجش ابعاد ساختار

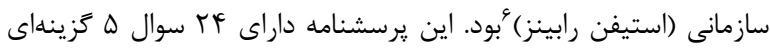

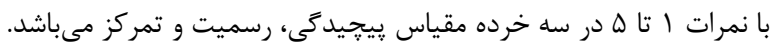

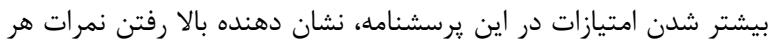

Formalization Complexity

Concentration

Stephen Robins

Cronbach's Alpha

Elmeri Index

دانشنامه صارم در طب بارورى

دوره ه، شماره f) - زمستان 
نتايج ركرسيون خطى جند گَانه نشان داد كه در ايستكاه ساب، فاكتورهاى

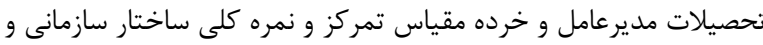

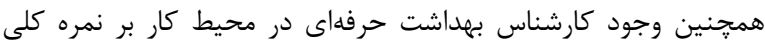

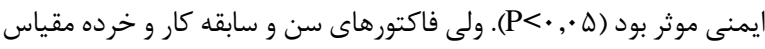

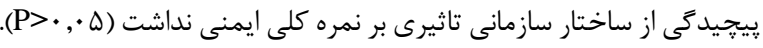

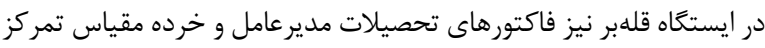

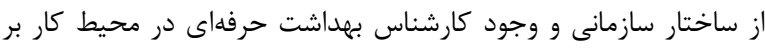

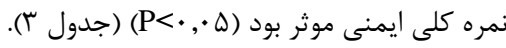

جدول rا: ضرايب ركرسيون خطى حند آنانه بين اثر عوامل مختلف بر نمرهى كلى ايمنى در

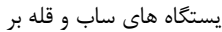

\begin{tabular}{|c|c|c|c|c|c|c|}
\hline \multirow{2}{*}{\multicolumn{2}{|c|}{ 'يستًاه }} & \multicolumn{2}{|c|}{$\begin{array}{l}\text { Unstandardized } \\
\text { Coefficients }\end{array}$} & \multirow{2}{*}{$t$} & \multirow{2}{*}{ Sig. } & \multirow{2}{*}{$\begin{array}{l}\text { Adjusted } \\
\text { R-square }\end{array}$} \\
\hline & & B & $\begin{array}{c}\text { Std. } \\
\text { Error }\end{array}$ & & & \\
\hline \multirow{8}{*}{ Polish } & مقدار ثابت & 53.858 & 22.448 & 2.399 & 0.019 & \multirow{8}{*}{0.578} \\
\hline & سن & 2.099 & 1.943 & 1.080 & 0.283 & \\
\hline & تحصيلات & 4.854 & 1.519 & 3.195 & 0.002 & \\
\hline & سابقه كار & 1.866 & 1.471 & 1.268 & 0.208 & \\
\hline & 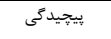 & 0.236 & 0.332 & 0.712 & 0.478 & \\
\hline & تمركز & 0.536 & 0.180 & 2.976 & 0.004 & \\
\hline & ساختار سازمانى & -1.245 & 0.540 & 2.307 & 0.024 & \\
\hline & كارشناس & 11.406 & 2.913 & 3.915 & 0.000 & \\
\hline \multirow{8}{*}{ Cutter } & مقدار ثابت & 29.201 & 26.677 & 1.095 & 0.277 & \multirow{8}{*}{0.632} \\
\hline & سن & 2.731 & 2.309 & 1.183 & 0.240 & \\
\hline & تحصيلات & 4.846 & 1.806 & 2.684 & 0.009 & \\
\hline & سابقه كار & 1.018 & 1.749 & 0.582 & 0.562 & \\
\hline & بيجيد & 0.406 & 0.394 & 1.032 & 0.305 & \\
\hline & تمركز & 0.586 & 0.214 & 2.736 & 0.008 & \\
\hline & ساختار سازمانى & -1.032 & 0.642 & 1.609 & 0.112 & \\
\hline & كارشت بهداس & 11.038 & 3.462 & 3.188 & 0.002 & \\
\hline
\end{tabular}

بحث

هدف از اين تحقيق، بررسى رابطه بين ابعاد ساختار سازمانى و وضعيت

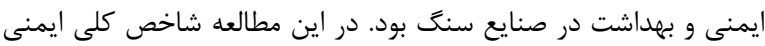

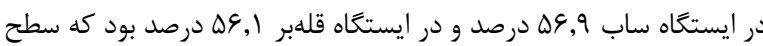

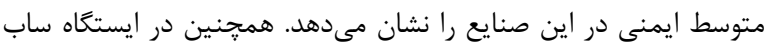

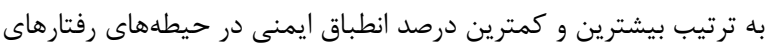

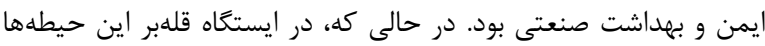

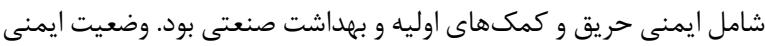

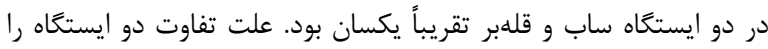

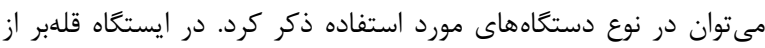

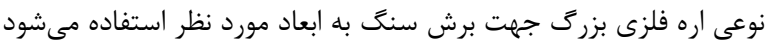

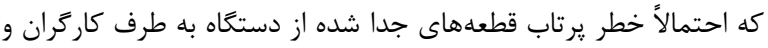

جدول ا: ميانكين و انحراف معيار نمرات ابعاد ساختار سازمانى و ايمنى در ايستكاههاى ساب

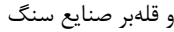

\begin{tabular}{|c|c|c|c|c|}
\hline \multicolumn{2}{|r|}{ ايستكاه } & \multirow{2}{*}{ ميانكيندانحراف } & \multirow{2}{*}{ ميانكيندانحراف } & \multirow[b]{2}{*}{$P$ value } \\
\hline 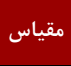 & مقياس خرد & & & \\
\hline \multirow{8}{*}{ 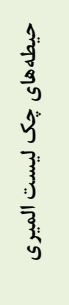 } & رفتارهاى ايمن & $74.44 \pm 43.86$ & $64.44 \pm 48.13$ & 0.147 \\
\hline & ضبط و ربط كار كاهى & $55.83 \pm 11.27$ & $55.92 \pm 11.30$ & 0.781 \\
\hline & ايمنى ماشين آلات & $60.55 \pm 12.97$ & $59.61 \pm 12.41$ & 0.647 \\
\hline & بهداشت صنعتى & $45.87 \pm 19.25$ & $45.17 \pm 19.10$ & 0.619 \\
\hline & 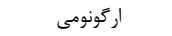 & $50 \pm 30.9$ & $53.88 \pm 26.47$ & 0.361 \\
\hline & مسيرهاى عبور و مرور & $60.74 \pm 31.83$ & $55.55 \pm 36.03$ & 0.308 \\
\hline & ايمنى حريق وكمكهاي اوليه & $61.94 \pm 20.94$ & $65.55 \pm 17$ & 0.206 \\
\hline & 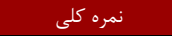 & $56.88 \pm 15.46$ & $56.13 \pm 16.22$ & 0.749 \\
\hline \multirow{4}{*}{ سازمانى } & بيجيديدى & \multicolumn{2}{|c|}{$50 \pm 8.9$} & -- \\
\hline & رسميت & \multicolumn{2}{|c|}{$54.3 \pm 16.8$} & -- \\
\hline & تمركز & \multicolumn{2}{|c|}{$73.6 \pm 14$} & -- \\
\hline & ساختار كلى ل لى & \multicolumn{2}{|c|}{$61.1 \pm 3.8$} & -- \\
\hline
\end{tabular}

همبستكى خطى در ايستخاه ساب، بين نمره كلى ايمنى و بهداشت با بعد

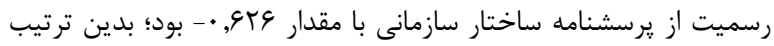

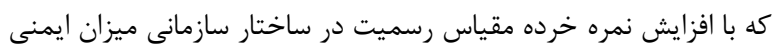

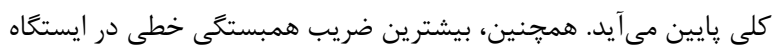

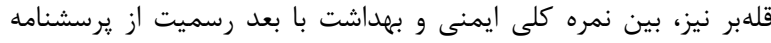

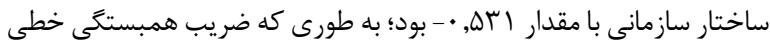

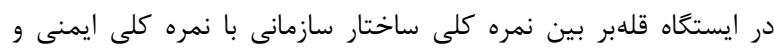

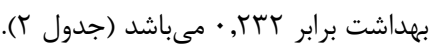

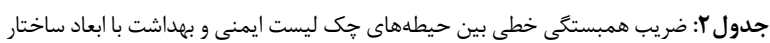
سازمانى در ايستخاه هاى ساب و قله بر بر حبر

\begin{tabular}{|c|c|c|c|c|c|}
\hline ايستكاه & ايمنى و بهداشت & يبحيدىى & رسميت & تمركز & نمره كلى \\
\hline \multirow{8}{*}{$\begin{array}{l}3 \\
3 \\
3 \\
3 \\
3\end{array}$} & رفتارهاى ايمن & $-0.381^{* *}$ & $-0.425^{* *}$ & $0.397^{* *}$ & -0.205 \\
\hline & ضبط و ربط & $-0.315^{* *}$ & $-0.364^{* *}$ & $0.357^{* *}$ & -0.142 \\
\hline & ايمنى ماشين آلات & $-0.277^{* *}$ & $-0.308^{* *}$ & $0.237^{*}$ & $-0.231^{\circ}$ \\
\hline & بهداشت صنعتى & $-0.313^{* *}$ & $-0.387^{* *}$ & $0.342^{* *}$ & -0.194 \\
\hline & اركونومى & $-0.485^{* *}$ & $-0.558^{* *}$ & $0.478^{* *}$ & $-0.328^{* *}$ \\
\hline & مسيرهاى عبور و & $-0.451^{* *}$ & $-0.482^{* *}$ & $0.440^{* *}$ & $-0.262^{*}$ \\
\hline & كمكنى حريق و & $-0.388^{* *}$ & $-0.456^{* *}$ & $0.388^{* *}$ & $-0.266^{*}$ \\
\hline & نمره كلى & $-0.558^{* *}$ & $-0.626^{* *}$ & $0.554^{* *}$ & $-0.348^{* *}$ \\
\hline \multirow{8}{*}{ 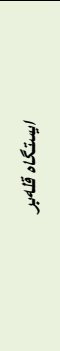 } & رفتارهاى ايمن & $-0.313^{* *}$ & $-0.387^{* *}$ & $0.342^{* *}$ & -0.194 \\
\hline & ضاركاهي و ربط & $-0.259^{*}$ & $-0.334^{* *}$ & $0.346 * *$ & -0.079 \\
\hline & ايمنى ماشين آلات & -0.152 & -0.129 & 0.099 & -0.123 \\
\hline & بهداشت صنعتى & $-0.313^{* *}$ & $-0.387^{* *}$ & $0.342^{* *}$ & -0.194 \\
\hline & اركونومى & $-0.461^{* *}$ & $-0.529^{* *}$ & $0.515^{* *}$ & $-0.217^{*}$ \\
\hline & مسيرهاى عبور و & $-0.356^{* *}$ & $-0.456^{* *}$ & $0.413^{* *}$ & -0.203 \\
\hline & كمكهاي اوليه و & $-0.391^{* *}$ & $-0.463^{* *}$ & $0.459^{* *}$ & -0.165 \\
\hline & نمره كلى & $-0.440^{* *}$ & $-0.531^{* *}$ & $0.494^{* *}$ & $-0.232^{*}$ \\
\hline
\end{tabular}


ناشى از كار و قرار دادن پِاداش براى رعايت موارد ايمنى با تعداد حوادث

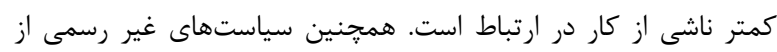

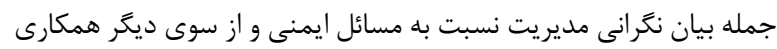

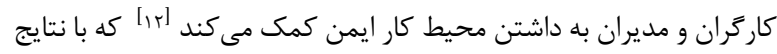

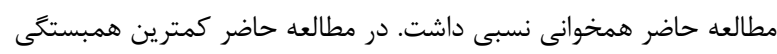

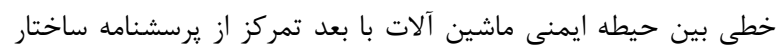

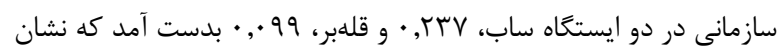

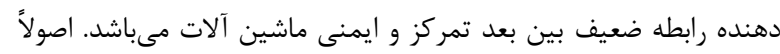

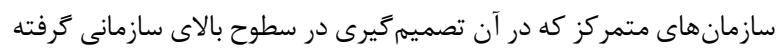

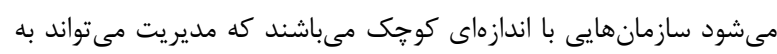

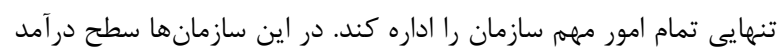

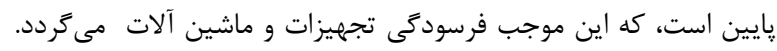

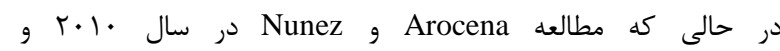

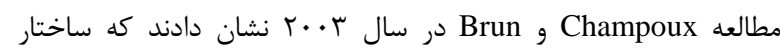

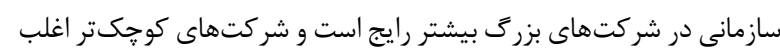

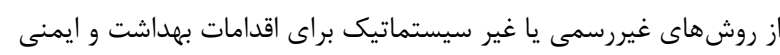

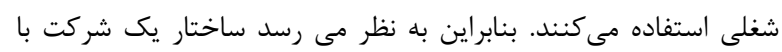

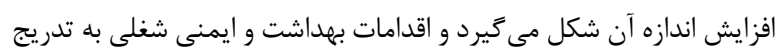

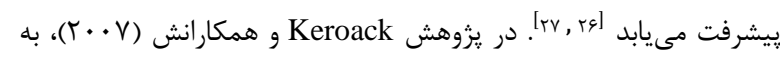

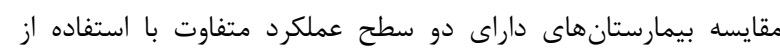

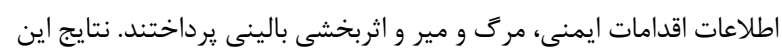

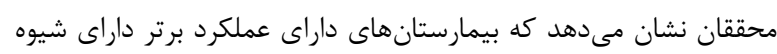

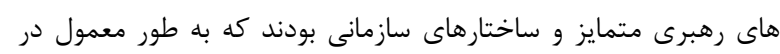

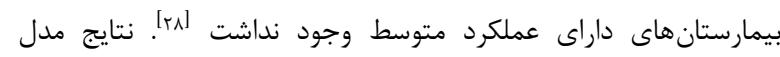

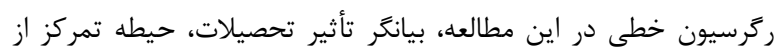

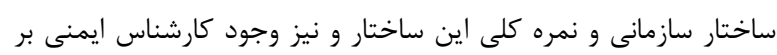

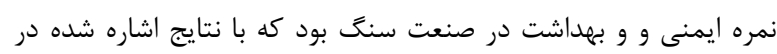
قسمت همبستخى مطابقت داشت.

\section{نتيجه كيرى}

نتايج مطالعه حاضر نشان مى دهد كه به طور كلى بين رسميت از مؤلفههاى

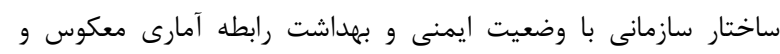

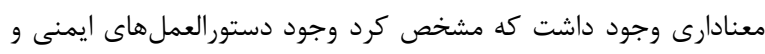

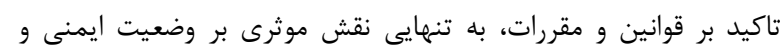

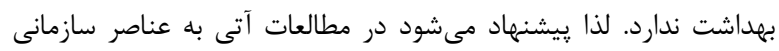

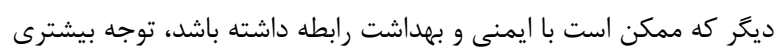

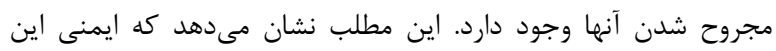

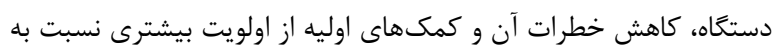

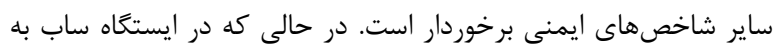

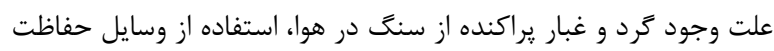

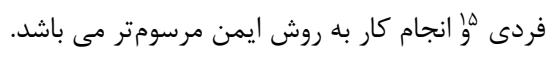

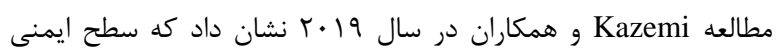

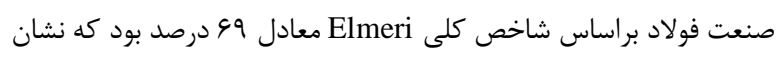

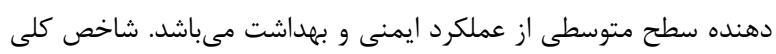

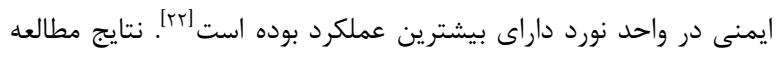

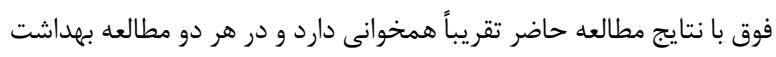

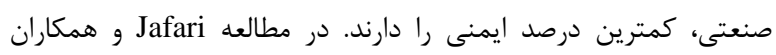

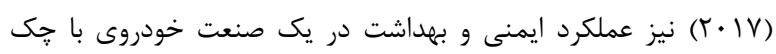

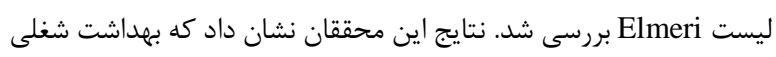

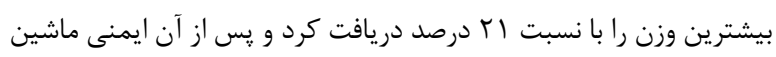

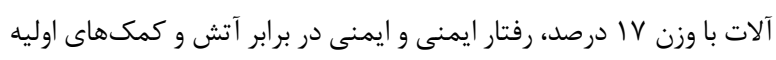

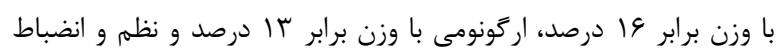

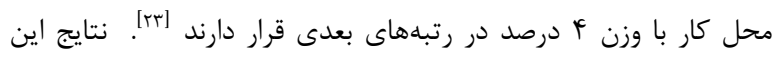

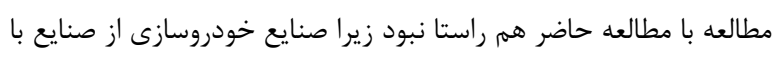

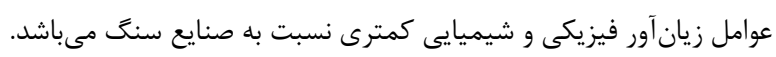

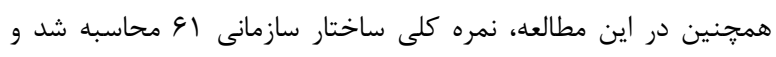

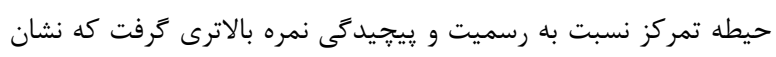

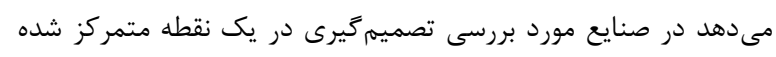

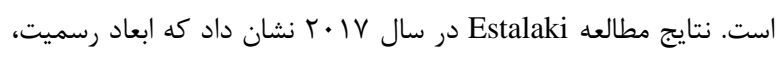

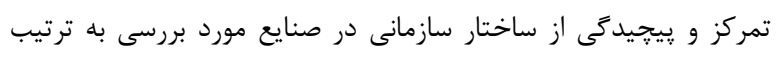

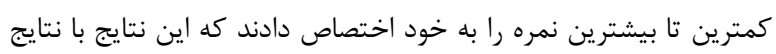

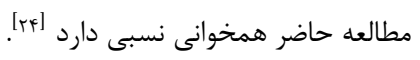

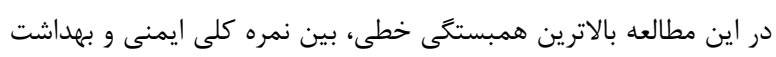

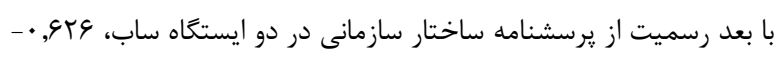

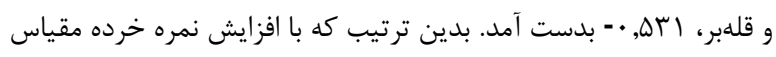

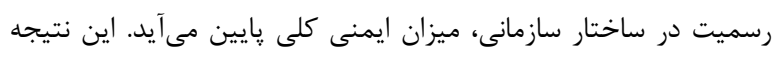

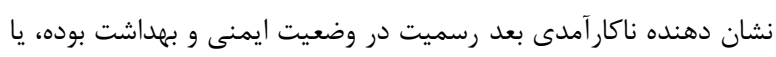

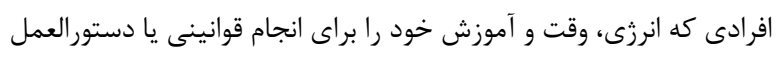

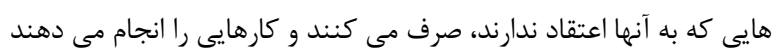

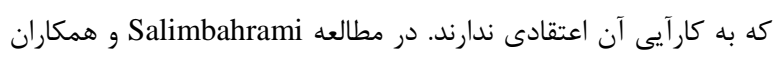

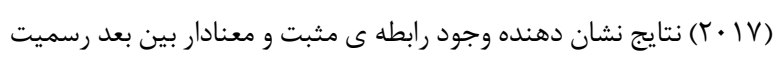

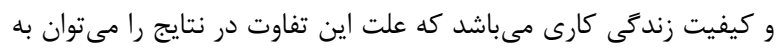

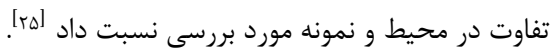

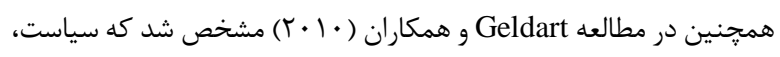

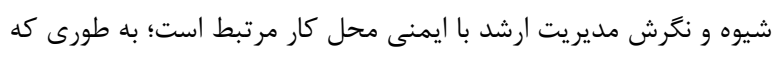
سياست هاى رسمى مثل تعهد مديريت نسبت بـا به ايمنى، بررسى حوادث

Personal Safety Equipment (PSE) ${ }^{10}$

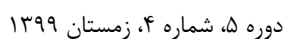


rates in manufacturing. Am. J. Ind. Med. 29, 258268 (1996).

$10 . \quad$ Hunt, H. A., Habeck, R. V., VanTol, B. \& Scully, S. M. Disability prevention among Michigan employers, 1988-1993. (1993).

11. Habeck, R. V, Leahy, M. J., Hunt, H. A. \& Chan, F. Employer factors related to workers' compensation claims and disability management. Rehabil. Couns. Bull. (1991).

12. Geldart, S., Smith, C. A., Shannon, H. S. \& Lohfeld, L. Organizational practices and workplace health and safety: A cross-sectional study in manufacturing companies. Saf. Sci. 48, 562-569 (2010).

13. Chahardoli, S., Motamedzade, M., Hamidi, Y., Soltanian, A. R. \& Golmohammadi, R. Investigating the relationship between psychosocial work stressors, organizational structure and job satisfaction among bank tellers. Heal. Saf. Work 5, 47-58 (2015).

14. Wilson, M. G., Dejoy, D. M., Vandenberg, R. J., Richardson, H. A. \& Mcgrath, A. L. Work characteristics and employee health and wellbeing: Test of a model of healthy work organization. J. Occup. Organ. Psychol. 77, 565588 (2004).

15. van den Berg, T. I. J. et al. The influence of psychosocial factors at work and life style on health and work ability among professional workers. Int. Arch. Occup. Environ. Health 81, 1029-1036 (2008).

16. Sivacoumar, R., Jayabalou, R., Swarnalatha, S. \& Balakrishnan, K. Particulate matter from stone crushing industry: size distribution and health effects. J. Environ. Eng. 132, 405-414 (2006).

17. Ilyas, M. \& Rasheed, F. Health and environment related issues in stone crushing in Pakistan. South Asia Netw. Econ. Res. Institutes 10-18 (2010).

18. HATAMI, S., Sobhani, Y. \& Beyrami Igder, J. The Effect of Organizational Structure on Empowerment of Staff of Sport and Youth General Office of Lorestan Province. J. Sport Manag. 7, 533-546 (2015).

19. Kenis, P. \& Raab, J. Back to the future: Using organization design theory for effective organizational networks. Perspect. Public Manag. Gov. 3, 109-123 (2020).

20. Nasiripour, A. A., Raeissi, P., Nagaf Bagy, R. \& Adabi, A. The survey of structural
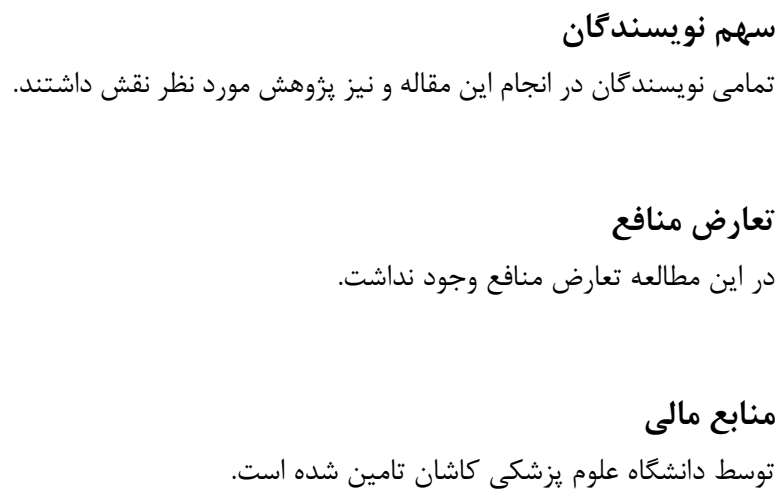

1.

Kawakami, T. \& Kogi, K. Ergonomics support for local initiative in improving safety and health at work: International Labour Organization experiences in industrially developing countries. Ergonomics 48, 581-590 (2005).

2. Itasca, I. L. National Safety Council: injury facts, 2001 ed. Itasca, Natl. Saf. Counc. (2001).

3. Yilmaz, F. \& Çelebi, U. B. The importance of safety in construction sector: Costs of occupational accidents in construction sites. Bus. Econ. Res. J. 6, 25 (2015).

4. Grimani, A. et al. Economic evaluation of occupational safety and health interventions from the employer perspective: A systematic review. J. Occup. Environ. Med. 60, 147 (2018).

5. Rzepecki, J. Cost and benefits of implementing an occupational safety and health management system (OSH MS) in enterprises in Poland. Int. J. Occup. Saf. Ergon. 18, 181-193 (2012).

6. Baicker, K., Cutler, D. \& Song, Z. Workplace wellness programs can generate savings. Health Aff. 29, 304-311 (2010).

7. Hymel, P. A. et al. Workplace health protection and promotion: a new pathway for a healthier-and safer-workforce. J. Occup. Environ. Med. 53, 695-702 (2011).

8. Loeppke, R. R. et al. Integrating health and safety in the workplace: how closely aligning health and safety strategies can yield measurable benefits. J. Occup. Environ. Med. 57, 585-597 (2015).

9. Shannon, H. S. et al. Workplace organizational correlates of lost-time accident 
factors in general hospitals of Yazd-Iran based on mechanic and organic approach 2012. Tolooebehdasht 12, 194-204 (2013).

21. Leroi, E., Bonnard, C., Fell, R. \& McInnes, R. Risk assessment and management. in Landslide risk management 169-208 (CRC Press, 2005).

$22 . \quad$ Kazemi, R., Nematpour, L. \& Jazayeri, S. A. Assessment of Safety and Health Performance Based on ELMERI Index in One of the Steel Industries in Khuzestan Province, Iran. J. Occup. Hyg. Eng. Vol. 5, 8-16 (2019).

23. Jafari, A., Choobineh, A., Jahangiri, M. \& Keshavarzi, S. An index developed for the assessment of occupational health and safety at workplace: A field study in a heavy automotive industry in the northwest of Iran. J. Heal. Sci. Surveill. Syst. 5, 86-93 (2017).

24. Estalaki, K. G. On the impact of organizational structure on organizational efficiency in industrial units: Industrial units of Kerman and Hormozgan Provinces. Estação Científica (UNIFAP) 7, 95-105 (2017).

25. Salimbahrami, S. H., Ahmadi, H., Zabihihajikolaei, F. \& Mahmudi Sahebi, H. The relationship between organizational structure and the quality of working life of employees. $J$. Process Eng. 4, 67-84 (2017).

26. Arocena, P. \& Núñez, I. An empirical analysis of the effectiveness of occupational health and safety management systems in SMEs. Int. small Bus. J. 28, 398-419 (2010).

27. Champoux, D. \& Brun, J.-P. Occupational health and safety management in small size enterprises: an overview of the situation and avenues for intervention and research. Saf. Sci. 41, 301-318 (2003).

28. 28. Keroack, M. A. et al. Organizational factors associated with high performance in quality and safety in academic medical centers. Acad. Med. 82, 1178-1186 (2007). 